\title{
Screening of Connexin 26 in Nonsyndromic Hearing Loss
}

\author{
Danielle Moreira ${ }^{1}$ Daniela da Silva ${ }^{1} \quad$ Priscila Lopez $^{1} \quad$ Jair Cortez Mantovani ${ }^{1}$

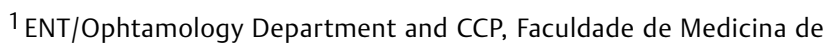 \\ Botucatu, Botucatu, São Paulo, Brazil \\ Int Arch Otorhinolaryngol 2015;19:30-33. \\ Address for correspondence Daniela da Silva, MSc, Departamento de \\ Oftalmologia/Otorrinolaringologia e CCP, Faculdade de Medicina de \\ Botucatu, Distrito de Rubião Júnior s/n, Botucatu 18618970, São Paulo, \\ Brazil (e-mail: daniela-polo@uol.com.br).
}

\begin{abstract}
Introduction The first locus for nonsyndromic autosomal recessive hearing loss is on chromosome $13 q 11-22$. The $35 \mathrm{del}$ G mutation is present in $80 \%$ of cases in which GJB2 is involved, which makes the study of this mutation very important. The viability and benefits of screening for mutations in the connexin 26 gene are now beginning to change the diagnostic evaluation and identification of the etiology of hearing loss.

Objective To investigate the occurrence of the $35 \mathrm{delG}$ mutation in patients with nonsyndromic sensorineural hearing loss and their first degree relatives.

Methods This transversal study included 72 patients from the local hospital. The patients were divided into three groups: group A, sensorineural hearing loss $(n=58)$; group B, first-degree relatives of group A with sensorineural hearing loss $(n=09)$; and group $C$, first-degree relatives of patients from group A without hearing loss ( $n=05)$. All patients had audiological evaluation and genetic testing of the 35delG mutation.

Results The 35 delG mutation was found in four heterozygous mutations (three of them found in the same family). The other heterozygous mutation was found in a female patient with bilateral, moderate, prelingual, sensorineural hearing loss. A single homozygous mutation was found in a male patient, with severe sensorineural hearing

Keywords

- acoustic stimulation

- genetics

- hearing loss

loss in his right ear and profound hearing loss in the left ear.

Conclusions The $35 \mathrm{del}$ m mutation was found in $7 \%$ of the cases. The test is easy to perform and inexpensive, but it is necessary to investigate other genes related to hearing loss.
\end{abstract}

\section{Introduction}

Hearing loss is the most common sensory deficit and limits social life; $60 \%$ of idiopathic prelingual hearing loss has a genetic basis, most of them being nonsyndromic. ${ }^{1-3}$ It is estimated that over 100 genes may be involved in nonsyndromic genetic deafness, and of these, $\sim 80 \%$ are associated with autosomal recessive, $15 \%$ autosomal dominant, 1 to $3 \%$ chromosome $\mathrm{X}$, and 0.5 to $1 \%$ mitochondrial mutations. ${ }^{4,5}$

The nonsyndromic hearing loss with a recessive pattern of transmission is characterized by prelingual sensorineural hearing loss, of severe or profound degree, and the dominant pattern of transmission can be conductive, sensorineural, or mixed, postlingual, and of progressive character. ${ }^{6}$

The first locus for nonsyndromic autosomal recessive hearing loss was identified in 1994 on chromosome 13q11-22. In 1997, the gene GJB2 (gap junction 32 ) was identified; it encodes the protein connexin 26 , the first nuclear gene related to syndromic deafness. ${ }^{7}$

Immunocytochemical studies showed that connexin 26 is present in the human cochlea from the 22nd week of embryonic development, and its function is to recycle potassium ions in the hair cells of the inner ear, especially in the cells of the organ of Corti, the limbus, and the spiral ligament. ${ }^{8,9}$ The received

February 5, 2014

accepted

February 28, 2014

published online

April 11, 2014
DOI http://dx.doi.org/

10.1055/s-0034-1373783. ISSN $1809-9777$.
Copyright $\odot 2015$ by Thieme Publicações License terms Ltda, Rio de Janeiro, Brazil

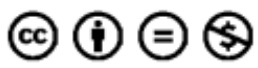


GJB2 gene is involved in both dominant and recessive nonsyndromic deafness. Among the cases of autosomal recessive pattern deafness, the $35 \mathrm{delG}$ mutation, which corresponds to the loss of a guanine base in the DNA sequence of the GJB2 at the 35 th position, stands out. ${ }^{10}$ The $35 \mathrm{delG}$ mutation is present in $80 \%$ cases in which GJB2 is involved, which makes the study of this mutation very important. ${ }^{7}$

According to Piatto et $\mathrm{al}^{11}{ }^{11}$ interest in the prevalence and types of mutations that cause nonsyndromic hearing loss in Brazil, with sample population studies, led to a newborn genetic screening program across the country. This program could lead to significant cost reduction and improvements in public health. The viability and benefits of screening for mutations in the connexin 26 gene are now beginning to change the diagnostic evaluation and identification of the etiology of hearing loss. In addition to the traditional audiological tests like audiometry, tympanometry, otoacoustic emissions, evoked auditory brainstem, among others, recent studies show the importance of early identification of etiology of hearing loss through genetic studies.

The objective of this study was to identify the occurrence of 35delG mutation in the GJB2 gene in patients with nonsyndromic sensorineural hearing loss and first-degree relatives with and without hearing loss.

\section{Methods}

This study was approved by the Ethics Committee in Research, protocol number 3333-2009, and all study participants signed a consent form. It was a clinical transversal study, from November 2009 to May 2011.

The clinical criteria for eligibility of the sample with nonsyndromic sensorineural hearing loss included meeting at least one of the following conditions: congenital, indeterminate etiology, no risk indicators for hearing loss in the neonatal period, with familial recurrence.

The study included 72 patients, 67 with nonsyndromic sensorineural hearing loss and 5 with normal hearing. These cases were divided in groups as follows. Group A included 58 cases with hearing loss, 33 females and 25 males, with ages ranging from 1 to 73 years. Group B included 9 cases (firstdegree relatives of group A) with sensorineural hearing loss, 6 females and 3 males, with ages ranging from 8 to 58 years. Five individuals (first-degree relatives of group $A$, one male and four females, with ages between 13 and 38 years with normal hearing) were included in the study because only they had normal hearing in the family and, according to the literature, the appearance of the 35delG mutation in heterozygosis does not necessarily cause hearing loss in the individual. ${ }^{10}$ Thus these individuals formed a new group, group $\mathrm{C}$.

The "test of genetic deafness"-35delG mutation screening of GJB2 gene on chromosome 13q1-examines the region of the connexin 26 gene by polymerase chain reaction (PCR); the test checks whether the region shows the most common mutation in cases of genetic deafness, the 35delG mutation, which occurs on the long arm of chromosome 13. It is called the "hot spot" of the gene, a place susceptible to modify, probably because of the deletion of the guanine base. It is a safe and fast test. ${ }^{10}$

Molecular analysis of the GJB2 gene was done as patented by researchers related to Campinas State University for extraction of DNA on filter paper and performing PCR to identify the 35delG by the DLE laboratory (Diagnostic Laboratory Specialized, Rio de Janeiro, Brazil). Before DNA extraction, two perforations of $3.0 \mathrm{~mm}$ were assigned to each patient and then separate DNA was extracted. At the end of the extraction process, the target DNA remained on the filter paper, and all cell debris and other potential inhibitors of the reaction were removed. For PCR, two reactions were assembled separately, one to specific primers for the normal pattern and another specially designed for the identification of the mutation studied. Reactions were prepared in volumes of $30 \mu \mathrm{L}$, and positive and negative controls were used for the validation routine. The amplification products were subjected to electrophoresis on 1.5\% agarose gel with $1 \times$ Thermocycler Applied Biosystem (TBE) buffer, at $9 \mathrm{~V} / \mathrm{cm}$. In parallel, a fragment size marker was used ads a parameter for the electrophoretic run. The alleles of each sample were visually identified by exposure to ultraviolet ray light after staining with ethidium bromide.

Analysis results were described by the DLE laboratory as "normal" when the 35delG mutation was absent and "abnormal" when heterozygous or homozygous 35delG mutation was present.

\section{Results}

The data were submitted to a descriptive statistical analysis. The majority of the patients of this study were white, with asian, black, and mixed less frequent (-Table 1).

Audiological tests showed all subjects in groups A, B, and C had tympanometry type A; they did not show changes in the middle ear. Transient evoked otoacoustic emissions and

Table 1 Distribution of ethnic groups

\begin{tabular}{|l|l|l|l|l|l|l|l|l|}
\hline & \multicolumn{2}{l}{ Asian } & \multicolumn{2}{l|}{ White } & \multicolumn{2}{l|}{ Black } & \multicolumn{2}{l|}{ Mixed } \\
\hline Groups & $\boldsymbol{n}$ & $\%$ & $\boldsymbol{n}$ & $\%$ & $\boldsymbol{n}$ & $\%$ & $\boldsymbol{n}$ & $\%$ \\
\hline A & 3 & 5.2 & 53 & 91.4 & 1 & 1.7 & 1 & 1.7 \\
\hline B & - & - & 9 & 100 & - & - & - & - \\
\hline C & - & - & 5 & 100 & - & - & - & - \\
\hline Total & 3 & 4.2 & 67 & 93 & 1 & 1.4 & 1 & 1.4 \\
\hline
\end{tabular}


Table 2 Distribution of the time of onset of hearing loss in groups $A$ and $B$

\begin{tabular}{|l|l|l|l|l|}
\hline & \multicolumn{2}{|l|}{ Prelingual } & \multicolumn{2}{l|}{ Postlingual } \\
\hline Groups & $\boldsymbol{n}$ & $\%$ & $\boldsymbol{n}$ & $\%$ \\
\hline A & 39 & 67.3 & 19 & 32.7 \\
\hline B & 3 & 33.3 & 6 & 66.7 \\
\hline Total & 42 & 62.7 & 25 & 37.3 \\
\hline
\end{tabular}

distortion product results were similar for groups A and B, $90 \%$ of nonresponses. Group C showed 100\% presence of both emissions transient and product of distortion. Pure tone audiometry showed $100 \%$ of ears in group $C$ had normal hearing, and groups A and B had predominantly sensorineural loss in moderate to profound degrees. The majority of group A participants had deafness before language development, and in group B, the hearing loss started late (-Table 2 ).

The screening of the $35 \mathrm{delG}$ mutation showed that most subjects in the three groups had negative results, but two cases in groups A and B had positive results with $35 \mathrm{delG}$ heterozygous GJB2 and only one case, in group A, had positive result with 35delG homozygous GJB2 (- Table 3).

\section{Discussion}

Breakthroughs in genetic research into hearing made clear the importance of studies of mutations in the gene GJB2, due to the ease of detection of mutations in the connexin 26 , which causes injury to the inner ear and thus can lead to the onset of hearing loss. In our study, 72 individuals were evaluated, and the results of genetic screening for the 35delG GJB2 mutation revealed five mutations with a prevalence of $1: 14$. The occurrence of variations found between other studies could be explained by differences in populations, methodological criteria, or perhaps ethnic heterogeneity of the population. ${ }^{10-16}$ Therefore, it is important to create a multicenter initiative that will address the issue genotype/ phenotype-related deafness in the Brazilian population.

In our study, through genetic screening of 35delG $C x 26$, we found four heterozygous mutations, three of them occurring in the same family: father (38 years), mother (28 years), both from group C, and son ( 5 years), from group A, affected. In this family, in relation to audiological findings, the parents had normal hearing and the (single) child had prelingual, severe, bilateral, sensorineural hearing loss. This emphasizes the importance of counseling, because the risk of recurrence of the genotype is imminent. The other heterozygous mutation was found in a 38-year-old woman from group A, with prelingual, moderate, bilateral, sensorineural hearing loss; in this case, the 35delG mutation was also screened in her deaf twin sister, but the result was negative. Hoffman et al reported the genetic and audiological profile of three brothers, all with prelingual, moderately severe, sensorineural hearing loss and found the same genetic diversity, two with 35delG mutation in heterozygosis and one without this change. ${ }^{14}$

The only mutation found in 35delG homozygotes in our sample was in a 20 -year-old man from group A, with prelingual sensorineural hearing loss of a severe degree in right ear and profound on the left. In this case, there was no recurrence of familial hearing loss, but it was not possible to evaluate the patient's first-degree relatives with normal hearing. However, it is possible to suppose the presence of Cx26 mutation 35delG in the patient's normally hearing parents, as the literature still shows no consensus on the correlation between the $35 \mathrm{delG}$ mutation and the presence, severity, or progression of hearing loss. ${ }^{10}$ The presence of the 35delG mutation in the heterozygous $C \times 26$ gene does not mean that the individual is deaf. ${ }^{10}$ Therefore, this suggests that there are other factors that modify the effects caused by the 35delG GJB2, possibly variations in other genes that compensate for the dysfunction of connexin 26 in the cochlear function.

The homozygous $C \times 26$ 35delG, in general, affected individuals with prelingual profound deafness, consistent with our finding. However, it is known that at birth the phenotype can vary from normal hearing to profound deafness, and, moreover, different degrees of hearing loss can be observed in individuals of the same family and with the same genotype. Given these facts, genetic counseling of individuals with the 35delG mutation becomes very important and also very problematic, as in general the degree and onset of hearing loss cannot be predicted based on the mutations found, so further studies in different populations are necessary to establish the relationship of genotype/phenotype to this mutation under study.

Hearing has an unquestionable importance to the development of conceptual processes that support human thought.

Table 3 Distribution of patients according to the screening of the $35 \mathrm{delG}$ mutation in groups A, B, and C

\begin{tabular}{|c|c|c|c|c|c|c|}
\hline \multirow[b]{2}{*}{ Groups } & \multicolumn{2}{|c|}{$\begin{array}{l}\text { Negative (absence of } \\
\text { the mutation) }\end{array}$} & \multicolumn{2}{|c|}{$\begin{array}{l}\text { Positive (35delG } \\
\text { heterozygous GJB2) }\end{array}$} & \multicolumn{2}{|c|}{$\begin{array}{l}\text { Positive (35delG } \\
\text { homozygous GJB2) }\end{array}$} \\
\hline & $n$ & $\%$ & $n$ & $\%$ & $n$ & $\%$ \\
\hline$A$ & 55 & 94.8 & 2 & 3.5 & 1 & 1.7 \\
\hline$B$ & 9 & 100 & - & - & - & - \\
\hline$C$ & 3 & 60 & 2 & 40 & - & - \\
\hline Total & 67 & 93 & 4 & 5.6 & 1 & 1.4 \\
\hline
\end{tabular}


In addition to individual effects, hearing loss has a substantial impact on social and economic development of communities and countries, in all ages and both sexes, and can cause significant social problems, especially isolation and stigmatization. Therefore, to prevent and minimize the effects of hearing loss in the population, it is necessary to find ways to make difference.

\section{Conclusions}

It was possible to investigate the mutation in the population studied, the research of the $35 \mathrm{delG}$ mutation was found to be easy to perform and inexpensive, and it is necessary to investigate other genes related to hearing loss.

\section{References}

1 Keogh IJ, Godinho RN. Genetic hearing loss. Ir Med J 2002;95:5-7

2 Murgia A, Orzan E, Polli R, et al. Cx26 deafness: mutation analysis and clinical variability. J Med Genet 1999;36(11):829-832

3 Parker MJ, Fortnum H, Young ID, Davis AC. Variations in genetic assessment and recurrence risks quoted for childhood deafness: a survey of clinical geneticists. J Med Genet 1999;36(2): $125-130$

4 Guilford P, Ben Arab S, Blanchard S, et al. A non-syndrome form of neurosensory, recessive deafness maps to the pericentromeric region of chromosome 13q. Nat Genet 1994;6(1):24-28

5 Kalatzis V, Petit $\mathrm{C}$. The fundamental and medical impacts of recent progress in research on hereditary hearing loss. Hum Mol Genet 1998;7(10):1589-1597

6 Petit C. Autosomal recessive non-syndromal hearing loss. In: Martini A, Read A, Stephens D, eds. Geneticas and Hearing loss. London, UK: Whurr Publishers Ltd.; 1996:197-212
7 Gasparini P, Rabionet R, Barbujani G, et al. High carrier frequency of the 35delG deafness mutation in European populations. Genetic Analysis Consortium of GJB2 35delG. Eur J Hum Genet 2000;8(1): 19-23

8 Alexandrino F, de Oliveira CA, Magalhães RF, et al. Connexin mutations in Brazilian patients with skin disorders with or without hearing loss. Am J Med Genet A 2009;15;149A(4):681-684

9 Forge A, Becker D, Casalotti S, et al. Gap junctions in the inner ear: comparison of distribution patterns in different vertebrates and assessement of connexin composition in mammals. J Comp Neurol 2003;467(2):207-231

10 Sartorato EL, Gotardi E, de Oliveira CA, et al. Determination of the frequency of the 35delG in Brazilian neonates. Clin Genet 2000; 58(4):339-340

11 Piatto VB, Oliveira CA, Alexandrino F, et al. Prospects for genetic hearing loss screening: 35delG mutation tracking in a newborn population. J Pediatr 2005;81(2):139-142

12 Piatto VB, Moreira OAV, Silva MAOM, Maniglia JV, Pereira MC, Sartorato EL. Correlation between audiometric data and the 35delG mutation in ten patients. Braz J Otorhinolaryngol 2007; 73(6):777-783

13 Magni C. Defieciência auditiva não- sindrômica: avaliação genética (genes de conexinas) e fenotípica (clínica e audiológica) (Tese). Curitiba, Brazil: Setor de Ciências Biológicas, Universidade Federal do Paraná; 2007

14 Hoffmann FM, Rodrigues PF, Santos TM, et al. Interaction between audiology and genetics in the study of a family: the complexity of molecular diagnosis and genetic counseling. Braz J Otorhinolaryngol 2008;74(5):698-702

15 Cordeiro-Silva MdeF, Barbosa A, Santiago M, et al. Prevalence of 35delG/GJB2 and del (GJB6-D13S1830) mutations in patients with non-syndromic deafness from a population of Espírito SantoBrazil. Braz J Otorhinolaryngol 2010;76(4):428-432

16 Nivoloni Kde A, da Silva-Costa SM, Pomílio MC, et al. Newborn hearing screening and genetic testing in 8974 Brazilian neonates. Int J Pediatr Otorhinolaryngol 2010;74(8):926-929 